\title{
Study on Thermal Expansion of a V10 Engine Block Used in Shrink-Fit Assembling
}

\author{
Sever-Alexandru HABA, Gheorghe OANCEA*
}

\begin{abstract}
The paper presents how a V10 engine block made of light alloys of aluminium is assembled with the cylinders casings made of grey cast iron alloys. The solution used in this case is shrink-fit technology. To obtain such an assembly it is required to study the phenomenon of thermal expansion of the bodies with complex geometries such as an engine block. The only viable solution to study the thermal phenomena for shrink-fit assembling is to use finite element methods for simulating. Five different cases are presented for the V10 engine block heating and for the optimal case, in which a clamping device is used for its positioning, the thermal expansions are determined. The final result is a mathematical relation which represents the dependences between the thermal expansions of the V10 engine block and temperatures.
\end{abstract}

Keywords: finite element analysis; shrink-fit assembling; thermal expansion; V10 engine block

\section{INTRODUCTION}

Due to current regulations on minimizing pollutant emissions, for the internal combustion engines used in vehicles and stationary equipment, the following construction features are requested: small displacement, very high power litres, lightweight, reduced fuel consumption, widespread use supercharging systems, very low emissions and reduced materials consumption in the manufacturing [1]. All these restrictions are dictated by the market demands and they are found in the construction of the main component of the internal combustion engine, respectively engine block.

In order to achieve an engine group with a very low weight was used constructive solution for assembling an engine block made from lightweight based on aluminium alloys with cylinders casings made of grey cast iron alloys.

The solution to obtain a lightweight engine block and assemble it with cylinders casings made from materials with high resistance to mechanical stress is widely used in building single-cylinder engines that equip light vehicles such as: ATV (All-Terrain Vehicle), motor bikes, stationary power pumps or electricity generating units $[1$, 2]. This solution is also widespread in the multi-cylinders engines fitted to motor vehicles designed for sports competitions.

The current solution of the multi-cylinders engine block made of light alloys is widely used in the field of general-purpose engines: engines for cars, motorcycle, motor groups stationary power generators or pumps and so on [1].

This paper is dedicated to the study of thermal deformation of an engine block which has to be assembled with a group of 10-cylinder casings in $\mathrm{V}$ normal, using shrink-fit technology.

\section{MANUFACTURING TECHNOLOGIES USED FOR A V10 ENGINE BLOCK}

The engine block is the fixed part of the engine group. It is the fixing base for all the other mechanical components of the system (engine mechanism and auxiliary systems). For this reason, the engine block shows a very complex geometry in $3 \mathrm{D}$ space. The modelling can be achieved by manipulation of solid bodies or by use of the advanced modelling of complex surfaces using the NURBS surfaces refining technologies (Non Uniform Rational B-Spline) [3]. In Fig. 1 is presented the CAD model of an engine block assembled with 10 cylinders $\mathrm{V}$-angle normal, with the following specifications:

- $\quad$ spark ignition engines;

- $\quad$ rated speed: $8000 \mathrm{~min}^{-1}$;

- $\quad$ engine displacement: $1874 \mathrm{~cm}^{3}$;

- maximum power: $375 \mathrm{CP}$;

- $\quad$ the number of cylinders: 10 ;

- bore: $70 \mathrm{~mm}$;

- $\quad$ stroke: $48.7 \mathrm{~mm}$

- $\quad$ star angle of the crankshaft crankpin: $72^{\circ}$.

Using CATIA V5 system [4], the 3D models of the engine block and the cylinders casings were designed separately, and then they were assembled. Fig. 2 presents a cross section through the engine block assembled with the cylinders casings. In the section the construction details can be observed, such as: holes for cylinders casings, channels for oil circulation lubrication system, complex channels for circulation of liquid cooling equipment, flat surfaces for positioning the cylinder head gasket, flat surface for oil pan mount and crankshaft holes.

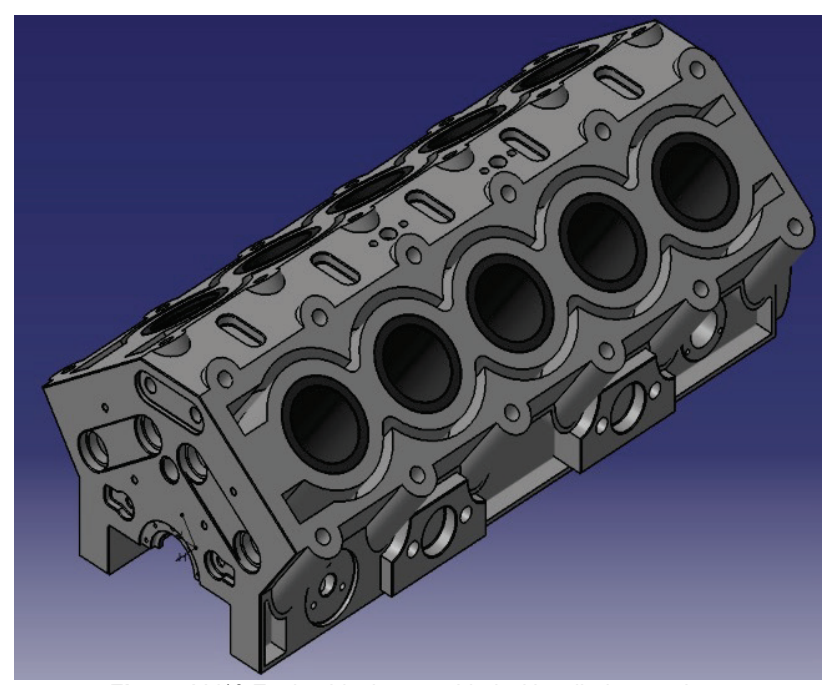

Figure 1 V10 Engine block assembled with cylinders casings

Nowadays the engines are designed according to the principles of pollution reducing in working and, also, in the manufacturing process. One of the environmental 
objectives of the cutting process is to eliminate the coolants [5] or to reduce at minimum the quantity of cooling lubrication (MQCL) [6, 7] using high speed machining process and microvideography [8].

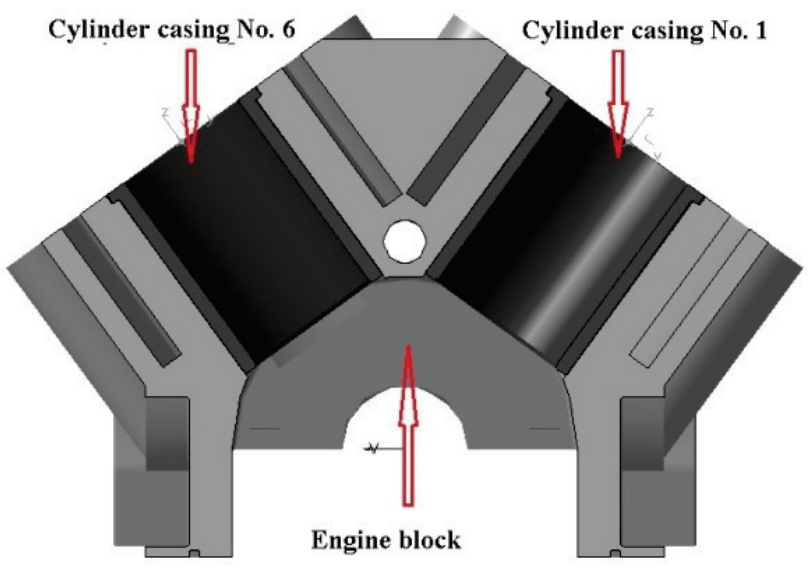

Figure 2 Section in engine block assembly

To manufacture this type of engine block the following stages are necessary [1]:

- engine block manufacturing:

- pressure die casting of the semi-finished part using light alloys of aluminium;

- cutting the necessary surfaces;

- cylinders casings manufacturing:

- centrifugal casting of semi-finished part for cylinders casings;

- cutting of functional surfaces of the parts.

- assembling of engine block with cylinders casings:

- $\quad$ achieving the temperature difference between the parts to be assembled;

- shrink-fitting between the engine block and the cylinders casings.

In order to optimize the process parameters of shrinkfit assembling it is necessary to determine the required temperatures for thermal expansions. For this purpose, the following equation can be used [9]:

$t=t_{0}+\frac{S_{\max }+j}{\alpha \cdot d} \cdot 10^{-3}$

where: $t$ is heating temperature, $t_{0}$ is environmental temperature, $S_{\max }$ is maximum of negative allowance, $j$ is clearance for insertion, $\alpha$ is coefficient of linear thermal expansion and $d$ is common diameter. The equation is used for parts with simple geometry, cylindrical sleeve type [9]. The calculation of thermal expansion holes in the body of the engine block (for bodies with complex geometries) was made using FEA (Finite Element Analysis).

In order to optimize the cost of non-demountable assembly of the engine block (made of light alloys) with proper cylinders casings the solution was chosen of increasing the engine block temperature in an oven and keeping the cylinders casings temperature at the environmental level $\left(20^{\circ} \mathrm{C}\right)$ [1].

To achieve prescribed temperature setting for the engine block, in all its mass, methods are recommended for determining the temperature without contact based on the median image filtering methods by infrared spectrum [10]. In other researches a method is implemented in a computer program which uses a high control volume finite method to determine thermal deformations [11]. It can be used measurement method, DIC (Digital Image Correlation), with no contact, to measure for different shapes, thermal deformations in very large temperature values $[12,13]$. The measured values can be compared with determined values in the process of simulation using finite element analysis.

In this study of shrink-fit assembly between the engine block and cylinders casings was calculated thermal expansion required at $0.20 \mathrm{~mm}$, the thermal expansion is useful not to damage the micro-profile contact surfaces of parts from the permanent jointed.

\section{FEA USED FOR THERMAL EXPANSION OF V10 ENGINE BLOCK}

Optimal method for determining the temperature of the engine block to be heated, in order to obtain the necessary thermal expansion for cylinders casings insertion in their holes, is the calculation of the necessary hot clearance fit, followed by modelling of the thermal expansion phenomenon using FEA method [14].

For the finite element analysis the user has available several software packages such as: ANSYS [15], ABAQUS (application included in the simulator package developed by Dassault Systems) [16], NASTRAN (application for multidisciplinary structural analysis developed by MSC Software) [17], Autodesk Simulation (application included in Autodesk products - developed by Autodesk) [18] and CATIA V5 (internal Analysis \& Simulation Module).

The authors used the CATIA V5 Analysis \& Simulation module for simulations of various case studies, and for optimal case to study the thermal expansions of casings holes from the 10 cylinders in $\mathrm{V}$-normal engine block.

The main parameter that provides a simulation of the thermal expansion phenomenon as close to reality (Global Error Rate sensor) is the type of finite element used, as the simulation performance increase to set a finite element parabolic shape (nonlinear finite element) or hexahedron form (available in the latest versions of CATIA environment) [19]. The modelling process parameters used in the study are presented in Tab. 1 .

Table 1 Parameters used in designing process

\begin{tabular}{|c|c|c|c|c|}
\hline $\begin{array}{c}\text { Element } \\
\text { size, } \mathrm{mm}\end{array}$ & $\begin{array}{c}\text { Absolute sag, } \\
\%\end{array}$ & Element type & Method & $\begin{array}{c}\text { Global error } \\
\text { rate, } \%\end{array}$ \\
\hline 10 & 0.2 & $\begin{array}{c}\text { Parabolic (high } \\
\text { performance) }\end{array}$ & auto & $<9$ \\
\hline
\end{tabular}

Fig. 3 presents the user coordinate system. Its position is on the centre upper surface of cylinder liners with $\mathrm{OX}$ axis oriented in the front of the engine block (the mechanism of distribution) and with $\mathrm{OZ}$ axis is normal to the surface of the engine block face. 


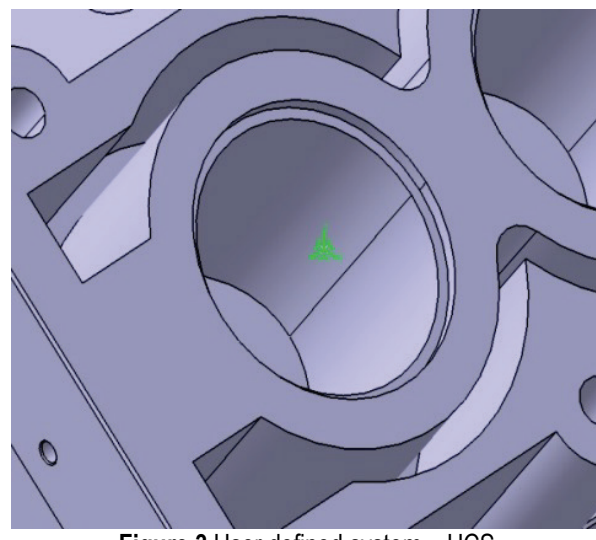

Figure 3 User defined system - UCS

For data extracting resulting in the finite element simulation are used the local and global sensors available in CATIA environment and presented in Tab. 2.

Table 2 Local and global sensors

\begin{tabular}{|c|c|}
\hline Global sensors & Local sensors \\
\hline $\begin{array}{c}\text { Global Error Rate (imposed value }<9 \%) ; \\
\text { Mass Maximum von Mises }\end{array}$ & Displacement Vector \\
\hline
\end{tabular}

Fig. 4 shows the structure of local and global sensors used for the FEA process and applied to thermal expansion of complex bodies.

In the case of the local sensors, used to determine the thermal expansion of cylinder liner holes (casing hole 1 ... casing hole 10), the following stages are used: insert the strain sensor type Displacement Vector for cylinder casing hole 1 - BOTTOM circular section (using only components $\mathrm{C} 1$ \& $\mathrm{C} 2$ - OX and $\mathrm{OY}$ axes corresponding components extracted by UCS user definable) and insert the strain sensor type Displacement Vector for cylinder casing hole 1 - TOP circular section (using only components C1 \& C2 - OX and OY axes corresponding components extracted by UCS user definable).

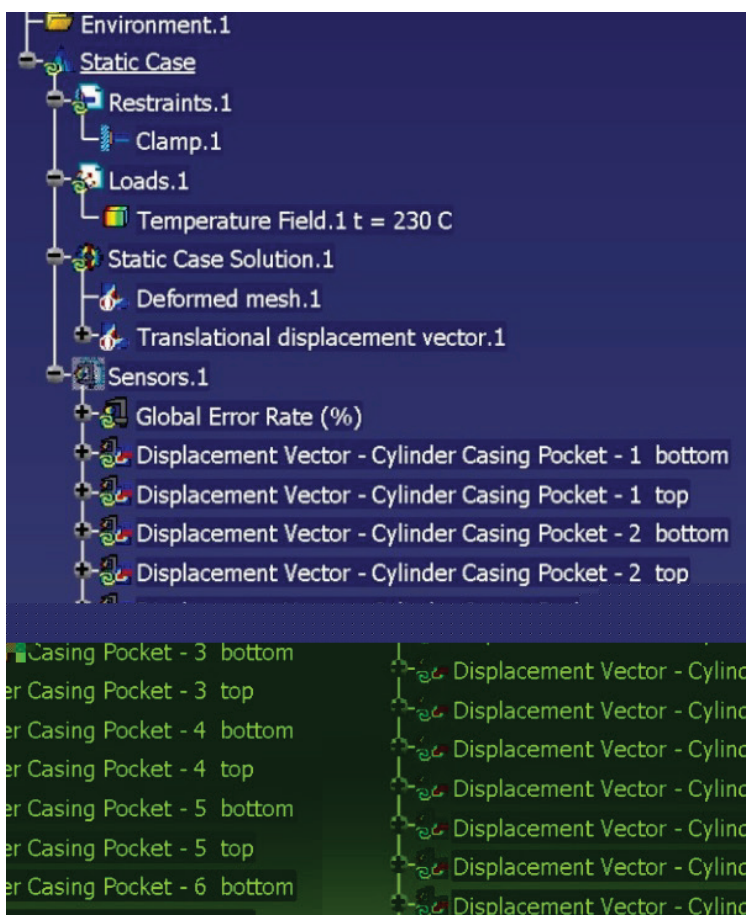

Figure 4 Local sensors for thermal expansion of cylinder holes

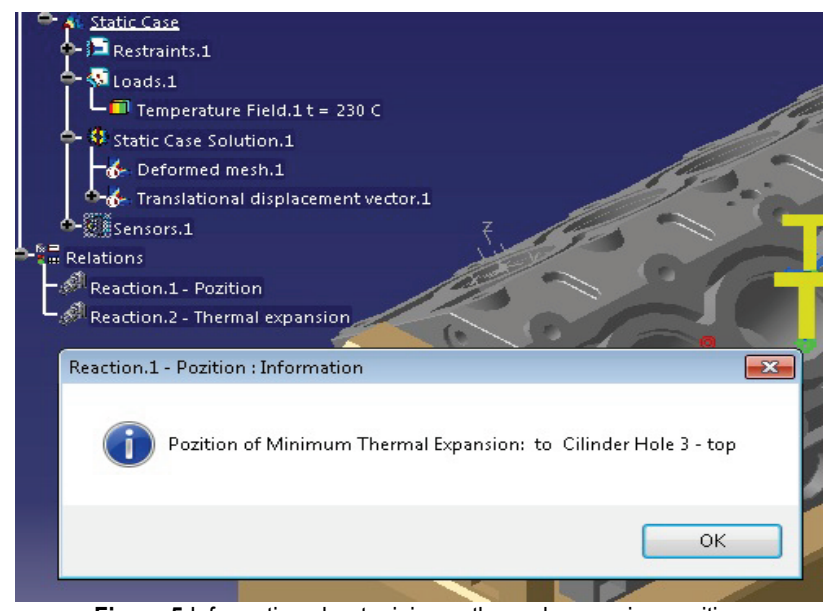

Figure 5 Information about minimum thermal expansion position

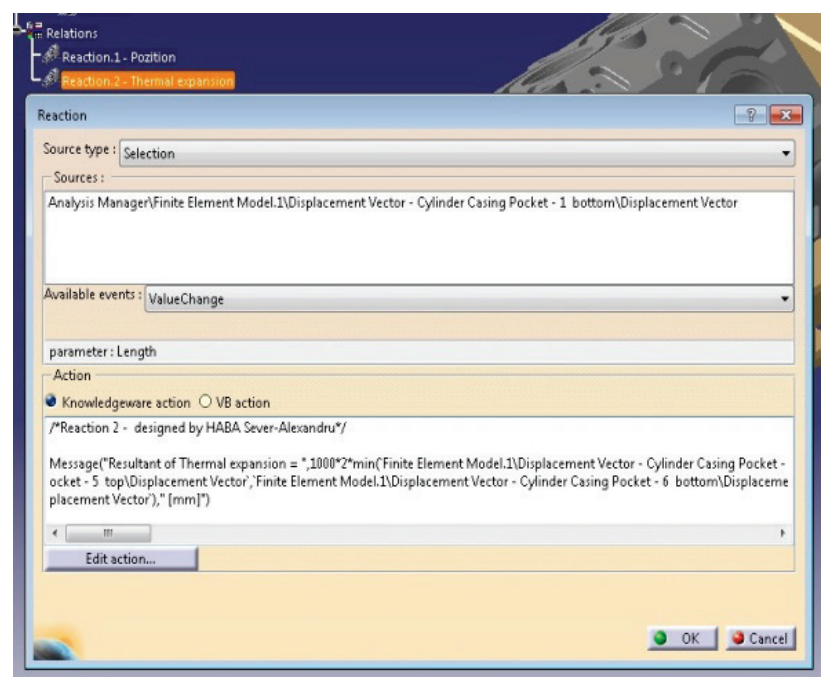

Figure 6 Information about minimum value

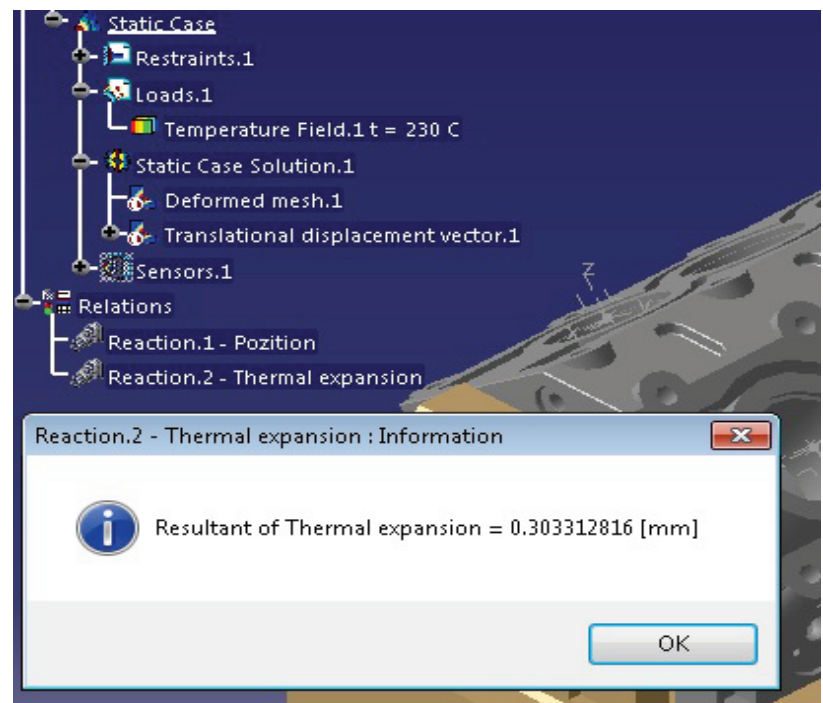

Figure 7 Information about resultant value of thermal expansion

In order to optimize the processing of data obtained on the value and position of the minimum thermal expansion two reactions were created. Reaction 1 (shown in Fig. 5) which is used to determine the number of the cylinder casing holes where there is the minimal expansion and shows the relative position (TOP or BOTTOM position) and reaction 2 (shown in Fig. 6) used for determining the minimum value of the thermal expansion with the following expression: 


$$
T h_{-} \exp =10^{3} \times 2 \times \operatorname{Min}\left(T h_{1}{ }_{\mathrm{TOP}}, T h_{1_{\mathrm{BOT}}}, \ldots\right)
$$

where: Th_exp is value of the thermal expansion processed, $T h_{1}{ }_{\mathrm{TOP}}, T h_{1_{\mathrm{BOT}}}, \ldots$ are the local thermal expansions of cylinder holes (TOP and BOTTOM sections).

In Fig. 7 is shown the dialog box for a thermal load value of $330{ }^{\circ} \mathrm{C}$, (the fixing case of the engine block is isostatic). It can be seen that at this temperature cylinder casing hole exceeds the minimum thermal expansion required for assembly, thus the heating level was taken to a lower value.

\section{THERMAL EXPANSION OF STUDIED V10 ENGINE BLOCK IN DIFFERENT CASES}

In order to relieve major influence on how to grip the workpiece during the heating process of the thermal expansion five cases were considered.

In the first case the part is fixed using three contact faces: Front, Rear and Bottom (Fig. 8) and in the second case the part is fixed with a single contact face, fixing that occurs by sitting front part corresponding contact area with the engine oil panel (Fig. 9).

The third case supposes that the part is fixed by only one contact face, respectively along the threaded bolts in the holes screws the oil pan mounting. This case corresponds to the real situation of the engine group operating (Fig. 10).

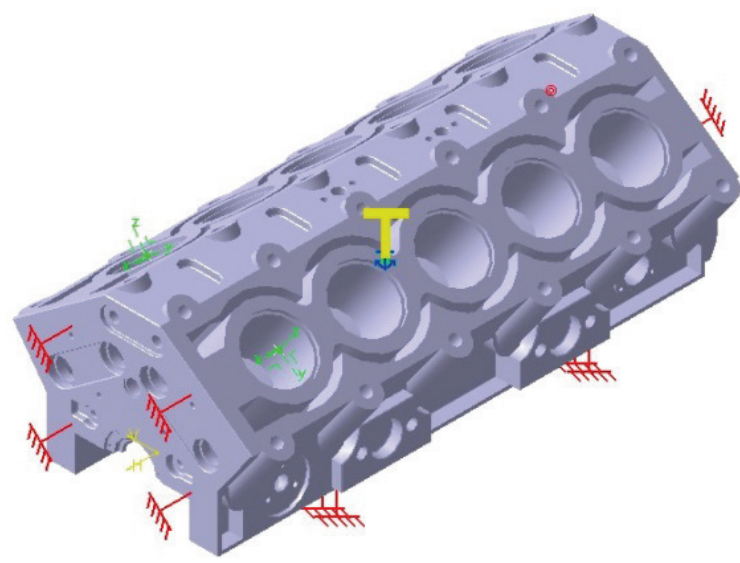

Figure 8 Case 1 - three fixing faces

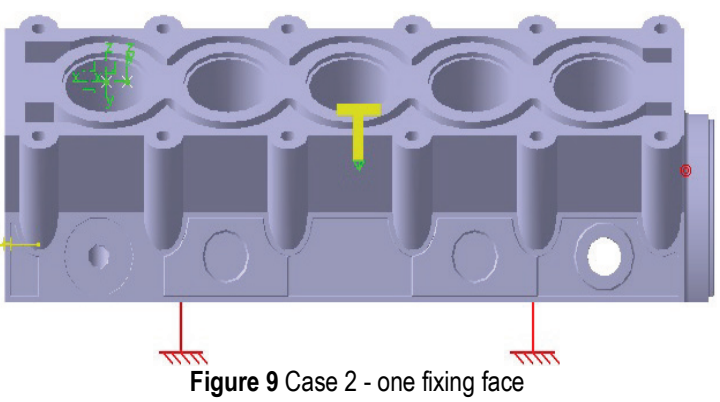

In the fourth case the part is in isostatic mode, this is only one theoretical solution, thus in the CATIA system one point in the part structure is immobilized, automatically determined by the finite element modelling software in an optimal position (see Fig. 9) [20].

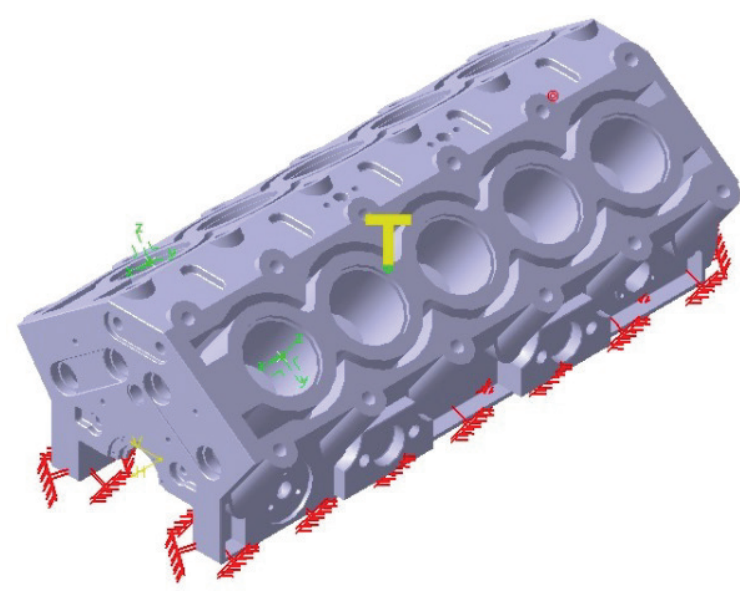

Figure10 Case 3 - 14 fixing holes
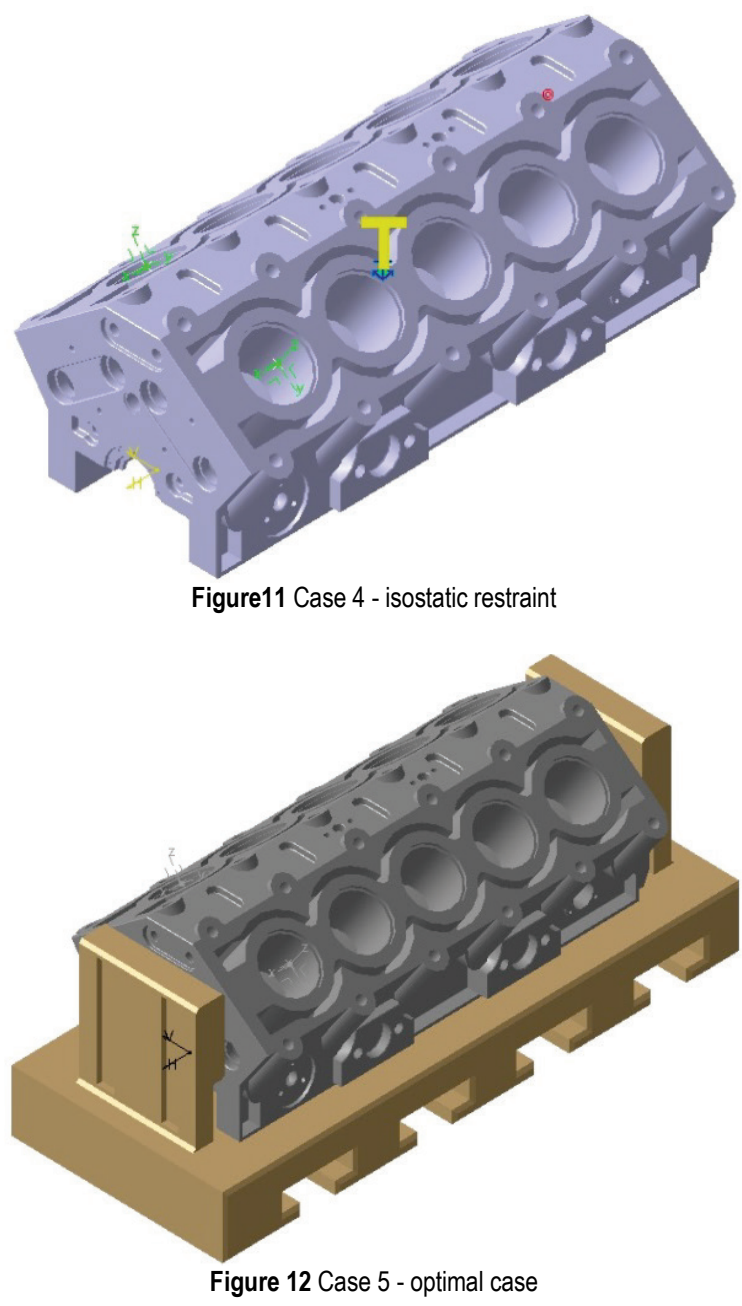

In the fifth case, the part is fixed in a technological clamping system used in the CNC manufacturing process (Fig. 12). The part is immobilized by the following procedures: Rear, Front and Bottom surfaces which are connected with the clamping device with "fastened Connection" restraint and the clamping device is immobilized along the contact surface with the processing machine table by "Clamp restraint". In this way, for heating process of the engine block, the virtual model corresponding to the technology used in the manufacturing process is implemented. It is followed by the automated assembling of the 10 cylinder casing at the standard ambient temperature, which is $20^{\circ} \mathrm{C}$. 
Thermal expansion $=\mathbf{f}($ construction solutions, thermal expansion: 0.20 [mm] )

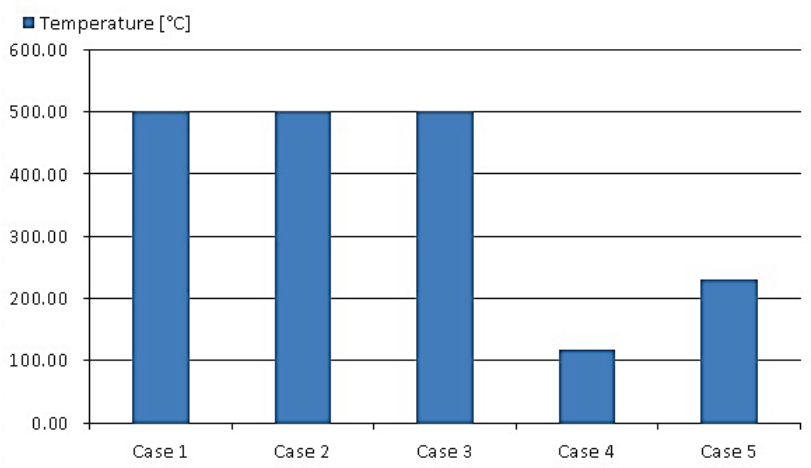

Figure 13 Thermal expansions - comparison between all cases

Following successive load model with different values of the temperature was obtained a series of values of thermal expansion resulting in proper cylinder casing mounting holes; the comparison of the obtained results is presented in the graphic form in Fig. 13. It shows that cases $1,2,3$ required temperatures that exceed the point of changing the mechanical property of the light alloys of aluminium and case 4 is a theoretical one. It requires a temperature for which the thermal expansion does not fulfil the conditions necessary to achieve shrink-fit technology (is excessively low temperature). Case 5 represents the real situation, and it is the appropriate solution for the shrinkfit assembling.

\section{THERMAL EXPANSION OF ENGINE BLOCK FIXED IN A TECHNOLOGICAL CLAMPING DEVICE}

The final stage of the FEA procedure for thermal expansion phenomenon, applied to the engine block mounted in the clamping device, is to determine the values of cylinder casing holes deformations for different temperatures at which the studied system is loaded.

Fig. 14 shows the deformed shape of the cylinder block assembly/clamping device. It can be easily seen that the maximum deformation occurs in the central part heated to achieve optimal heat shrink-fit assembling at $230^{\circ} \mathrm{C}$.

The process parameters used in this complex case are presented in Tab. 3 .

Table 3 Parameters used in FEA process

\begin{tabular}{|c|c|c|c|c|c|}
\hline \multicolumn{2}{|c|}{ Engine block } & \multicolumn{2}{|c|}{ Clamping device } & \multirow[b]{2}{*}{ Element type } & \multirow{2}{*}{$\begin{array}{l}\text { Global } \\
\text { error } \\
\text { rate, } \%\end{array}$} \\
\hline $\begin{array}{l}\text { Element } \\
\text { size, } \mathrm{mm}\end{array}$ & $\begin{array}{l}\text { Absolute } \\
\text { sag, \% }\end{array}$ & $\begin{array}{l}\text { Element } \\
\text { size, } \mathrm{mm}\end{array}$ & $\begin{array}{c}\text { Absolute } \\
\text { sag, } \%\end{array}$ & & \\
\hline 9 & 0.2 & 15 & 0.2 & $\begin{array}{l}\text { Parabolic (high } \\
\text { performance) }\end{array}$ & $<9$ \\
\hline
\end{tabular}

The mesh resolution for the engine block structure was set at a lower value than the clamping device in order to ensure an optimal processing time without affecting the accuracy of modelling physical phenomena.

Following the FEA simulation, the reaction dedicated to establish the position to the minimum thermal expansion reveals that the minimum required thermal expansion is obtained in the hole of cylinder casing number 3 , at the upper section of the hole. This area is detailed in Fig. 15.

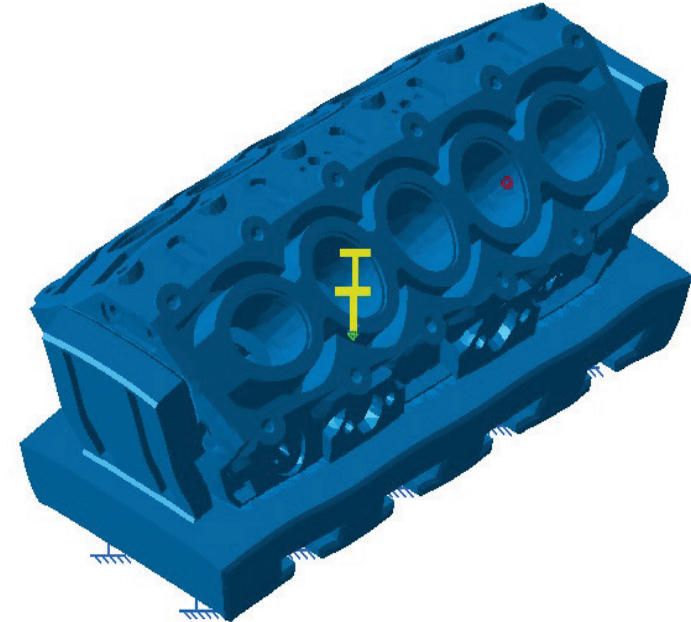

Figure 14 Deformed mesh in optimal case

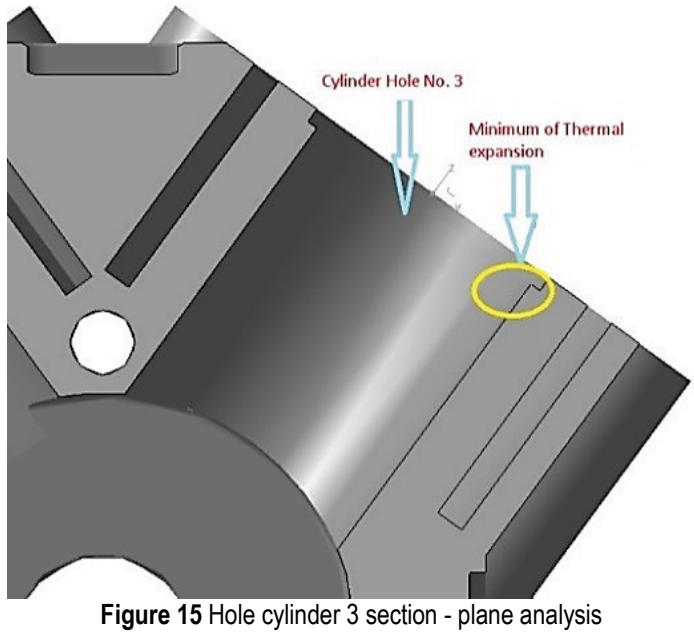

The area with the lowest thermal expansion coincides with the area where it starts placing the cylinder casing in corresponding hole from engine block. For this reason it is very important that heat clearance made after increasing the comprehensive part temperature (in this case the engine block) to ensure an assembly without damaging the surfaces micro-profile, that will maintain in optimal immobilization condition of the cylinder casing during the normal operation in the internal combustion engine assembly.

In order to generate the graph variation of the dependences between the thermal expansions of the assembly which consists of the engine block and clamping device, and heating temperatures, a total of nine FEM simulations were made. The temperatures values were in the range $190 \div 270{ }^{\circ} \mathrm{C}$ with a step value assigned to $10^{\circ} \mathrm{C}$. The obtained data were mathematically modelled and the studied phenomenon is materialized by the following equation:

$d=0.1517 \cdot \mathrm{e}^{0.048 \cdot t}$,

where: $t\left({ }^{\circ} \mathrm{C}\right)$ is the temperature and $d(\mathrm{~mm})$ is the thermal expansion. It can be observed that the overall dependence of thermal expansion and heating temperature describes an exponential form. 
Thermal expansion $=\mathrm{f}(\mathrm{t})$

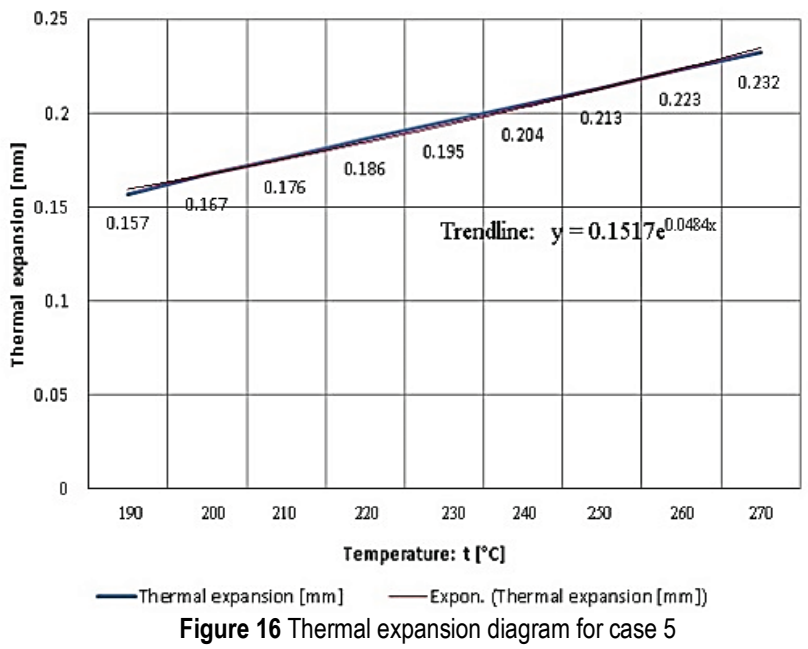

\section{CONCLUSION}

The paper presents simulation of the thermal expansion of a V10 engine block which is used in the shrink-fit technology with cylinders casings.

In order to create a finite element analysis corresponding to the real physical phenomenon of thermal expansion, it is necessary to use the model of the part to be simulated, mounted in proper clamping devices. The simulation of the influence of clamping device is developed with FEM tools in accordance with the technological steps used to obtain the final internal surfaces of engine cylinders casings (influence of thermal phenomena on the cylinder surface quality). The final result is a mathematical relation which models the phenomenon of thermal expansions. It allows calculating the thermal expansion for a specified temperature and for implementing in different software tools.

\section{Acknowledgements}

We hereby acknowledge the structural funds project PRO-DD (POS-CCE, O.2.2.1., ID 123, SMIS 2637, ctr. No $11 / 2009$ ) for providing the infrastructure

\section{REFERENCES}

[1] Haba, S. A. (2013). Digital Manufacturing of SingleCylinder Engine Block, PhD thesis, Transilvania University of Brasov, Romania.

[2] Haba, S. A. \& Oancea, G. (2015). Digital manufacturing of air-cooled single-cylinder engine block. The International Journal of Advanced Manufacturing Technology, 80(5), 747-759. https://doi.org/10.1007/s00170-015-7038-x

[3] Hughes, T. J. R., Cottrell, J. A., \& Bazilevs, Y. (2005). Isogeometric analysis: $\mathrm{CAD}$, finite elements, NURBS, exact geometry and mesh refinement. Computer Methods in Applied Mechanics and Engineering, 194(39-41), 41354195. https://doi.org/10.1016/j.cma.2004.10.008

[4] Cozzens, R. (2013). CATIA V5 Workbook Release V5 - 6R 2013, SDC Publications, Utah, USA.

[5] Varga, G. \& Kundrák, J, (2013). Effect of Environmentally Conscious Machining on Machined Surface Quality. Applied Mechanics and Materials, 309, 35-42. https://doi.org/10.4028/www.scientific.net/AMM.309.35
[6] Maruda, R. W., Feldshtein, E., Legutko, S., \& Krolczyk, G. M. (2015). Research on emulsion mist generation in the conditions of minimum quantity cooling lubrication (MQCL). Tehnicki vjesnik, 22(5), 1213-1218. https://doi.org/10.17559/TV-20140423221850

[7] Maruda, R. W., Feldshtein, E., Legutko, S., \& Krolczyk, G. M. (2016). Analysis of Contact Phenomena and Heat Exchange in the Cutting Zone under Minimum Quantity Cooling Lubrication conditions. Arabian Journal for Science and Engineering, 41(2), 661-668. https://doi.org/10.1007/s13369-015-1726-6

[8] Moraiti, M., Belis, T., Pappa, M., Kyratsis, P., Maravelakis, E., \& Antoniadis, A. (2016) Chip Formation Characteristics in High Speed Machining Utilizing High Speed Microvideography, Academic Journal of Manufacturing Engineering, 12(1), 6-13.

[9] Jula, A. (2016). Machinery parts course. Retrieved from: http://www.unitbv.ro.

[10] Giron, A. D. R. \& Correa H. L. (2013). Non-Uniform heating compensation for sequences of thermal images using median filtering. Dyna, 80(182), 74-82.

[11] Chareonsuk, J. \& Vessakosol, P. (2011). Numerical solution for functionally graded solids under thermal and mechanical loads using a high-order control volume finite element method. Applied Thermal Engineering, 31 (2-3), 213-227. https://doi.org/10.1016/j.applthermaleng.2010.09.001

[12] Strycker M., Schueremans L., Paepegem, W., \& Debruyne, D. (2010). Measuring the thermal expansion coefficient of tubular steel specimens with digital image correlation techniques. Optics and Lasers in Engineering, 48(10), 978986. https://doi.org/10.1016/j.optlaseng.2010.05.008

[13] Pan, B., Wu, D., Wang, Z., \& Yong, X. (2011). Hightemperature digital image correlation method for full-field deformation measurement at $1200{ }^{\circ} \mathrm{C}$. Measurement Science and Technology, 22(1), 1-11. https://doi.org/10.1088/0957-0233/22/1/015701

[14] Haba, S. A. \& Oancea, G. (2013). Thermal Expansion Analysis of the Complex Body Assemblies. Applied Mechanics and Materials, 309, 162-169. https://doi.org/10.4028/www.scientific.net/AMM.309.162

[15] Haba, S. A. \& Oancea, G. (2015). Studies on Thermal Contraction of Crankshaft Bearings under Extreme Low Temperatures. Journal of Thermal Science, 24(5), 496-501. https://doi.org/10.1007/s11630-015-0813-z

[16] Simulia - ABAQUS unified FEA brochure, from http:// www.3ds.com.

[17] MSC products, MSC Nastran Multidisciplinary Structural Analysis. Retrieved from: http://www.mscsoftware.com.

[18] Autodesk products, Autodesk Simulation portfolio. Retrieved from: http:// usa.autodesk.com.

[19] Nader, G. Z. (2011). CATIA V5 Release 20, FEA Tutorials, SDC Publication.

[20] Ghionea, I. G. (2009). CATIA V5 Applications in mechanical engineering, Bren Publishing, Bucharest.

\section{Contact information:}

\section{Sever-Alexandru HABA, PhD}

Transilvania University of Brasov,

Department of Manufacturing Engineering,

Mihai Viteazu Str., No. 5, Brasov, Romania

E-mail: habasever@yahoo.com

Gheorghe OANCEA, Professor, PhD

(Corresponding author)

Transilvania University of Brasov,

Department of Manufacturing Engineering,

Mihai Viteazu Str., No. 5, Brasov, Romania

E-mail: gh.oancea@unitbv.ro 